\title{
Solar UV Irradiance Measurements at Four Sites in Tibet
}

\author{
Norsang Gelsor ${ }^{1 *}$, Nima Pingcuo ${ }^{1}$, Tsoja Wangmu ${ }^{1}$, Berit Kjeldstad ${ }^{2}$, Yi-Chun Chen $^{3}$, \\ Øyvind Frette, Jakob J. Stamnes ${ }^{3}$, Binod K. Bhattarai ${ }^{4}$, and Arne Dhalback ${ }^{5}$ \\ ${ }^{1}$ Geophysics Institute, Tibet University, Lhasa, Tibet, P.R. China \\ ${ }^{2}$ Norwegian University of Science and Technology, N-7034 Trondheim, Norway \\ ${ }^{3}$ Department of Physics and Technology, University of Bergen, Norway \\ ${ }^{4}$ Institute of Engineering, Tribhuvan University, Nepal \\ ${ }^{5}$ Plasma and Space Physics, University of Oslo, Oslo, Norway
}

\begin{abstract}
We present solar ultraviolet (UV) irradiance measurements at four sites in Tibet (Lhasa, Linzhi, Nagqu, and Tingri) for the period between July 2008 and September 2010. Erythemal UV dose rates and irradiances of solar UVA, UVB for all four sites are presented. Days with clear sky cloud transmittance (CLT) larger than 100\% are particularly selected and analyzed for the four sites. Comparisons between the four sites are also carried out, and the clear-sky data analyses for the summer time show that Tingri (near Mt. Everest) has the highest UV irradiance, Lhasa the second highest, while Nagchu (Northen Tibet) and Linzhi (Eastern Tibet) have a bit lower values. Tingri has the strongest UV level among the four sites around the year, mainly due to increased albedo caused by snow-covered surroundings.

UV data for Lhasa for the period from 2004 to 2010 are also analyzed, showing that the UV instantaneous irradiance trend for the recent six-year period is stable. However, the number of clear-sky days in Lhasa has increased over the recent six years, causing an increase in the yearly-integrated total UV irradiance.
\end{abstract}

Keywords: Tibet, UV irradiance, clear-sky day number, trend

\section{Introduction}

At high altitudes in the Himalayan region, a special mountain meteorology may drive the atmospheric ozone transport process, resulting in an"ozone valley" (Zhou and Luo, 1994) of low stratospheric ozone values during spring and summer (Liu et al., 2003). Moreover, the shallow atmosphere due to the high altitude implies that more UV radiation reaches the surface, making this region an ideal natural laboratory for investigating surface UV radiation. The direct consequence of the ozone depletion is an increase in the level of solar UV radiation on the ground (Hester and Harrison, 2000), which may have both negative and positive impacts on materials, living things, and human health (Urbach, 1969). Therefore, changes in the solar UV radiation become a concern, particularly in polar areas and at high plateaus. The Tibetan plateau is the highest plateau on Earth, with thin air, little water vapor, and low aerosol content. Moreover, the low latitude of the Tibetan Plateau causes it to have a very high intensity of solar UV radiation on the ground (Norsang et al., 2009), prompting studies of solar UV radiation and its impacts.

In previous studies of solar UV radiation over the Tibetan plateau, Norsang et al. (2009) reported measurement results for Lhasa, Tibet, and Dhalback et al. (2007) and Ci Ren et al. (1997) reported some short term measurements in Tibet. To further study long-term UV and ozone 
climatology in the Himalaya region, a solar radiation and aerosol observatory network was established both in Tibet and Nepal in July 2008. The present report contains part of the measurement results from this new solar radiation and aerosol observatory network on the Tibetan plateau.

\section{Measurements and methods}

\subsection{Measurement sites and Instruments}

Four solar radiation (including UV radiation) and aerosol measurement sites were established on the Tibetan Plateau, Linzhi at $2995 \mathrm{~m}$ altitude in the eastern part of Tibet, Lhasa at $3683 \mathrm{~m}$ altitude in the middle of Tibet, Nagqu at $4510 \mathrm{~m}$ altitude in the north, and Tingri at $4335 \mathrm{~m}$ altitude in the west (near to Mt. Everest). Figure 1 shows pictures from the four sites in Tibet.

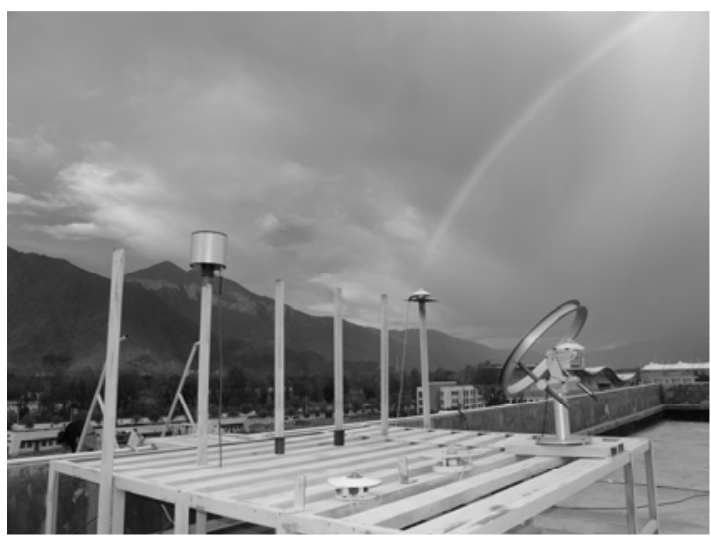

(a)

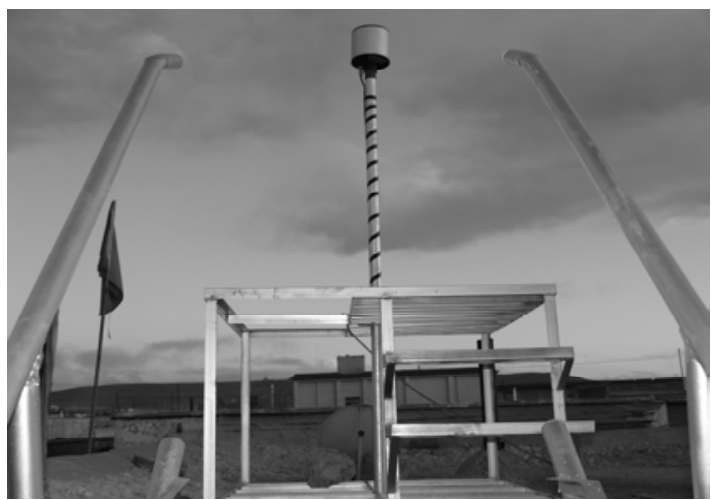

(c)

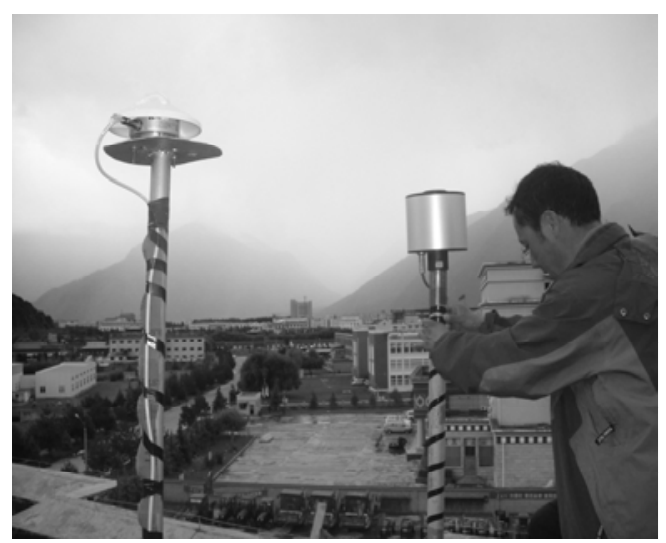

(b)

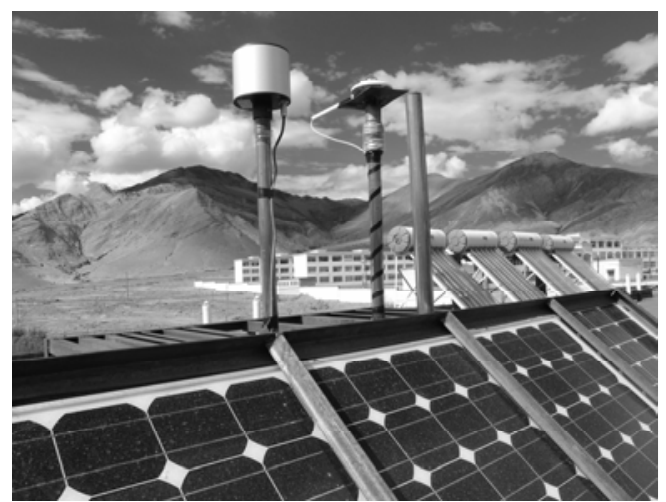

(d)

Figure 1: The four solar radiation and aerosol measurement sites in Tibet:

a) Lhasa b) Linzhi c) Nagqu and d) Tingri 
The instruments used for the measurements, their geographical coordinates, altitudes, and the starting dates for the measurements are given in Table 1.

Table 1: Four Solar Radiation and Aerosol Measurement Sites Established in Tibet

\begin{tabular}{|l|c|c|c|c|c|}
\hline Site & Instrument & Latitude & Longitude & Altitude & Starting Date \\
\hline Lhasa & NILU-UV127 & $29.646570^{\circ} \mathrm{N}$ & $91.177955^{\circ} \mathrm{E}$ & $3683 \mathrm{~m}$ & Jul 02, 2008 \\
\hline Linzhi & NILU-UV128 & $29.657889^{\circ} \mathrm{N}$ & $94.365132^{\circ} \mathrm{E}$ & $2995 \mathrm{~m}$ & Dec 13,2008 \\
\hline Nagqu & NILU-UV129 & $31.473719^{\circ} \mathrm{N}$ & $92.057518^{\circ} \mathrm{E}$ & $4510 \mathrm{~m}$ & Dec 07,2008 \\
\hline Tingri & NILU-UV138 & $8.655516^{\circ} \mathrm{N}$ & $87.129036^{\circ} \mathrm{E}$ & $4335 \mathrm{~m}$ & $\operatorname{Dec} 20,2008$ \\
\hline
\end{tabular}

Three of the four sites, namely Lhasa, Linzhi, and Tingri, are surrounded by mountains, while Nagqu is surrounded by small hills, as shown in Figure 1. We expect the effect of surrounding mountains to be small for high solar elevations but to be of greater importance for low solar elevations.

The NILU-UV irradiance meters used for measuring solar UV radiation in Tibet, were produced by the Norwegian Institute for Air Research (NILU, 2011). The newest version (version 2) of the NILU-UV irradiance meter, which was produced in 2008 , has better detectors, filters, and a more accurate clock inside. The data from the meter is recorded by the inbuilt data logger. The data are stored on the basis of average for each minute; however, the instrument monitors 2-3 samples in each second. In particular, the detectors are assumed to be more stable under harsh weather conditions. All UV irradiance meters used in this study were calibrated against a high-quality and well-characterized double monochromator spectroradiometer at the Norwegian Radiation Protection Authority (NRPA) in Oslo, Norway before they were deployed in Tibet. Since any UV irradiance meter may drift when deployed for measurement in the outside environment, each of the NILU-UV irradiance meters used in this study was equipped with a relative calibration unit having three calibration lamps, an Instec power supply, and a FLUKE multi-meter. In Tibet, relative calibrations are performed once per 10 day period to check drift caused by natural decay of filters and detectors. The relative calibrations are used to produce drift factors that are used to make corrections in the data analyses.

\subsection{Theoretical methods}

The NILU-UV irradiance meters can measure or deduce the following physical quantities:

1. Daily erythemal UV dose:

$$
D_{E r y}=\int_{d a y} \int_{280}^{400} A_{E r y}(\lambda) F_{\lambda} d \lambda d t
$$

where $F_{\lambda}$ is the spectral irradiance measured by the instrument at time t, and where $A_{E r y}(\lambda)$ is the erythema action spectrum, which describes the relative effectiveness of solar energy at different wavelengths in producing the erythema response. The erythema action spectrum represents the sensitivity of human skin to Sunburn, and is given by McKinlay and Diffey (1987) 


$$
A_{E r y}(\lambda)=\left\{\begin{array}{cc}
1, & \text { if } \lambda<298 \\
10^{-0.094(\lambda-298)}, & \text { if } 298 \leq \lambda<328 \\
10^{-0.015(\lambda-139)}, & \text { if } \lambda \geq 328
\end{array}\right.
$$

According to an algorithm given by Dahlback (1996), the daily erythemal dose derived from NILU-UV measurements is given by

$$
D_{\text {Ery }}=\int_{d a y}\left(a_{1} V_{1}(t)+a_{3} V_{3}(t)+a_{4} V_{4}(t)+a_{5} V_{5}(t)\right) d t
$$

which is a linear combination of the dose rate of four of the five UV channels of the NILU-UV instrument with center wavelengths at $302,312,320,340$ and $380 \mathrm{~nm}$. The coefficients $a_{\mathrm{i}}(\mathrm{i}=1$, $3,4,5)$ are dose factors, which depend on the chosen action spectrum. The accuracy of the dose determined with a filter instrument with these coefficients $a_{\mathrm{i}}$ will in general depend on the number of channels and their center wavelengths. The functions $V_{i}(i=1,3,4,5)$ are the voltages measured by the different UV channels.

2. The integrated daily UVA dose is defined by

$$
D_{U V A}=\int_{d a y} \int_{320}^{400} F_{\lambda} d \lambda d t
$$

and can be represented by NILU-UV measurements as

$$
D_{U V A}=\int_{d a y}\left(a_{3} V_{3}(t)+a_{5} V_{5}(t)\right) d t
$$

3. The integrated daily UV-B dose is defined by

$$
D_{U V B}=\int_{d a y} \int_{280}^{320} F_{\lambda} d \lambda d t
$$

and can be represented by NILU-UV measurements as

$$
D_{U V B}=\int_{d a y}\left(a_{1} V_{1}(t)+a_{3} V_{3}(t)\right) d t
$$

Data processing software for calculation of erythemal UV doses, integrated daily UVA and UVB irradiances comes with each NILU-UV instrument. The software also provides cloud cover assessment, total ozone abundances, and integrated PAR irradiances.

\section{Results and Discussions}

\subsection{Measured solar erythemal UV irradiance}

We present measured results of solar erythemal UV irradiance at the four sites. This large-scale and long-period measurement of solar UV radiation is the first systematic study of the UV climatology on the Tibetan plateau. The measured results show a general overview of UV radiation levels on the plateau. Daily erythemal UV dose were calculated based on the measured data for each of the four sites in Tibet. 

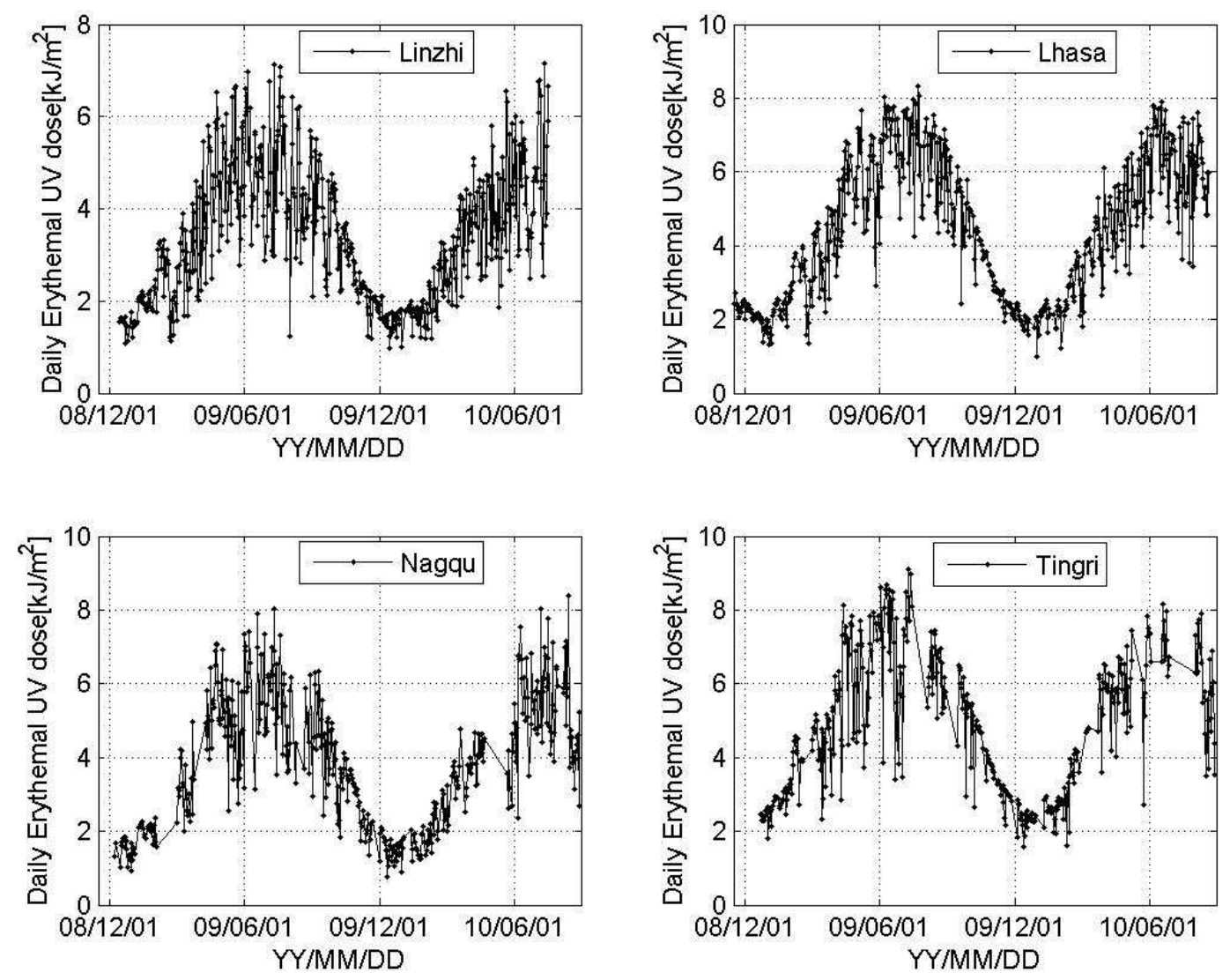

Figure 2: Measured daily erythemal UV doses at the four sites in Tibet for the time periods:

Lhasa Nov 15, 2008 - Aug 21, 2010; Linzhi Dec 14, 2008 - Jul. 20, 2010;

Nagqu Dec 15, 2008 - Aug. 30, 2010; and Tingri Dec 21, 2008 - Aug 31, 2010.

Figure 2 shows the measured daily erythemal UV dose in units of $\left[\mathrm{kJ} / \mathrm{m}^{2}\right]$, where each dot represents the value of the daily erythemal UV dose for all types of sky conditions, including clear skies, overcast skies, and partially cloudy skies. The fluctuations between nearby days are due mainly to cloud impact, which reduces and increases the UV levels on the ground as seen in Figure 2. It is seen that the clouds may reduce the surface UV irradiance by up to $80 \%$. In the contrast, partial cloud cover may increase the surface UV irradiance for cases in which clouds do not cover the disk of the sun. Then the reflections of sunlight from surrounding clouds may enhance the surface UV irradiance.

The measured results show that the daily erythemal UV doses in Tibet ranges from $0.99 \mathrm{~kJ} / \mathrm{m}^{2}$ to $9.11 \mathrm{~kJ} / \mathrm{m}^{2}$ during the measurement period. Table 2 shows more detailed value ranges for each site in Tibet. 
Table 2: Value ranges of daily erythemal UV doses at the four sites

\begin{tabular}{|c|c|c|c|c|}
\hline \multirow{2}{*}{ Site } & \multicolumn{2}{|c|}{ UV dose $\left[\mathrm{kJ} / \mathrm{m}^{2}\right]$} & \multirow{2}{*}{ CLT(\%) } & \multirow{2}{*}{ Ozone (DU) } \\
\hline & $\min$ & $\max$ & & \\
\hline Lhasa & $\begin{array}{c}1.0040 \\
(\operatorname{Dec} 31,2009)\end{array}$ & $\begin{array}{c}8.406 \\
\text { (Jul 8, 2008) }\end{array}$ & $39.1-112.4$ & $285.5-248.6$ \\
\hline Linzhi & $\begin{array}{c}0.9898 \\
\text { (Dec 15, 2009) }\end{array}$ & $\begin{array}{c}7.165 \\
\text { (Jul 14, 2010) }\end{array}$ & $98.6-107.5$ & $246.0-249.6$ \\
\hline Nagqu & $\begin{array}{c}0.7553 \\
\text { (Dec.11, 2009) }\end{array}$ & $\begin{array}{c}8.372 \\
\text { (Aug15, 2010) }\end{array}$ & $80.1-101.1$ & $258.8-225.9$ \\
\hline Tingri & $\begin{array}{c}1.5780 \\
(\text { Dec.13, 2009) }\end{array}$ & $\begin{array}{c}9.111 \\
\text { (Jul 10, 2009) }\end{array}$ & $85.2-117.8$ & $237.5-227.0$ \\
\hline
\end{tabular}

Table 2 shows the minimum and maximum values of daily erythemal UV doses derived from measurements at the four sites on specific days. Also shown are the corresponding cloud transmission (CLT) factors, and total ozone average values for the selected days which is calculated as defined in NILU (2008). The CLT describes the effect of clouds on the UV radiation, and is defined as (NILU, 2008):

$$
C L T=\frac{\text { channel_4(measured })}{\text { channel_4(clear_sky) }} \times 100 \%
$$

where channel_4(measured) is the irradiance measured by channel \#4, channel_4(clear_sky) is the clear-sky channel \#4 irradiance value calculated by including the spectral response of this channel. At sea level with no snow cover and clear sky, the CLT should be close to $100 \%$. Aerosols and clouds will lower the CLT, whereas partial cloud cover may increase the CLT, and at higher elevation the CLT will increase. Therefore in the Table 2 the maximum CLT values exceed $100 \%$, which means that the high elevation, possibly combined with a partial cloud cover, increases the value of CLT and the UV dose. Corresponding averaged total ozone values for the specific days are also listed in Table 2.

Figure 3 shows clear-sky daily erythemal UV doses at the four sites in Tibet. It shows that in Tingri, which has the highest UV irradiance among the four sites around the year, the maximum value reached $8.67\left[\mathrm{~kJ} / \mathrm{m}^{2}\right]$ on Jun. 11, 2009. Daily erythemal UV doses exceed $7.0\left[\mathrm{~kJ} / \mathrm{m}^{2}\right]$ during summer days for all stations. Linzhi has the lowest UV dose value among the four sites for most of the year. 


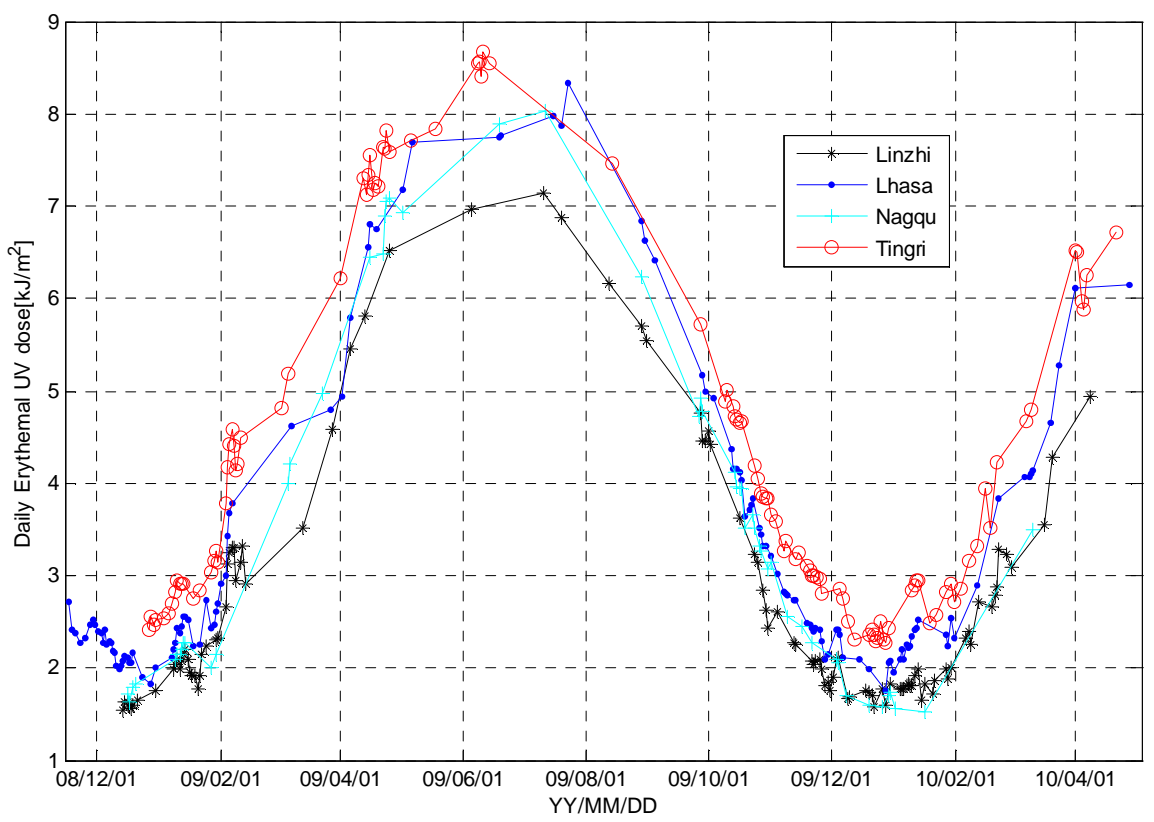

Figure 3: Daily erythemal UV doses for clear-sky days at the four sites in Tibet

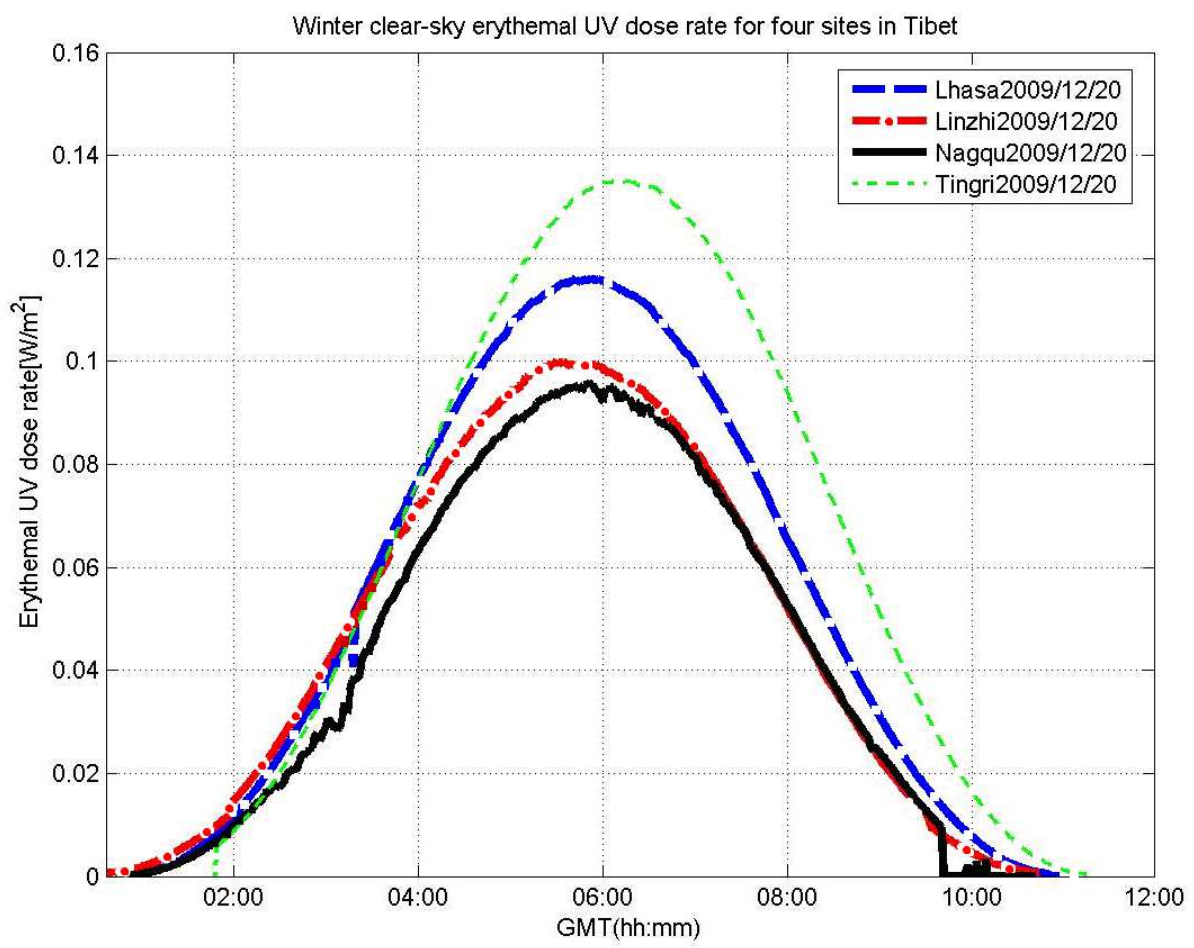

Figure 4: Comparison of erythemal UV dose rates between the four sites in Tibet 
To show the variation of erythemal UV dose rates on a clear-sky day among the four sites, we selected Dec. 20, 2009, which was a clear day at all four sites. Figure 4 shows the one-minute time interval variation of erythemal UV dose rates near winter solstice on Dec. 20, 2009 at the four sites in Tibet. The erythemal UV dose rates are seen to be highest in Tingri, which is only about $60 \mathrm{~km}$ away from Mt. Everest. Table 1 shows that Tingri has an altitude of $4335 \mathrm{~m}$, and the lowest latitude of $28.655516^{\circ} \mathrm{N}$, and possibly the highest surface albedo among the four sites since the surroundings of Tingri are bare ground and snow-covered mountains. Also, Tingri has a clean atmosphere, which will contribute to the high values of the UV irradiance. Linzhi has the lowest altitude and the lowest surface albedo (the surroundings are ground with grass cover and mountains covered by trees), which make its erythemal UV irradiance the lowest among the four sites. While Lhasa has second highest erythemal UV irradiance, mainly due to high surface albedo, the surroundings are mostly bare ground and mountains, and snows appear on tops of mountain occasionally. Nagqu has the highest altitude $(4510 \mathrm{~m})$ among the sites, but its latitude is highest $\left(31.473719^{\circ} \mathrm{N}\right)$ as well, contributing to reduce the UV radiation level. In addition, due to very cold weather conditions, local people in Nagqu burn firewood and cow dung around the year, making the atmosphere more polluted compared to other sites, and causing the UV radiation level on the ground to be reduced.

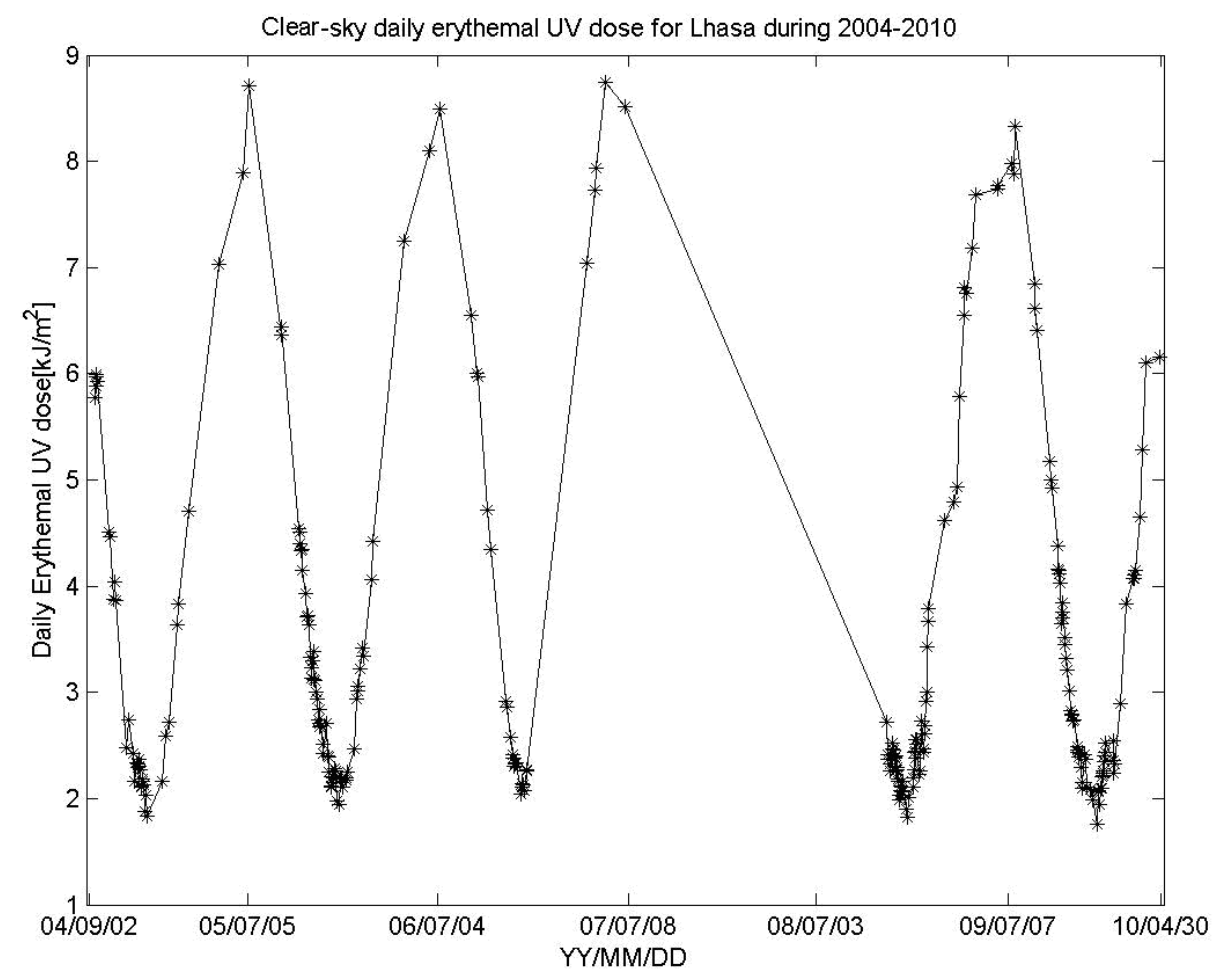

Figure 5: Measured values for clear-sky erythemal UV dose for Lhasa

A longer time series of UV measurements in Lhasa is presented in Figure 5, where only selected clear-sky daily erythemal UV doses are shown. The analysis shows that the UV irradiance level for Lhasa for the period from 2004 to 2010 is stable. However, the number of clear-sky days in Lhasa has increased over the recent six years, causing an increase in the yearly-integrated total UV irradiance. 


\subsection{Measured solar UVA and UVB irradiance}

Solar UVB radiation has a disproportionately large photobiological effect (Tevini, 1993). Plants, animals, and humans are greatly affected by strong UVB radiation. Figure 6 shows measured results for the daily UVB doses at the four sites in Tibet for the time period of Nov. 15, 2008 Aug. 31, 2010. As expected, the daily-integrated UVB dose at each station is seen to reveal low values during the winter, and very high values during the summer.
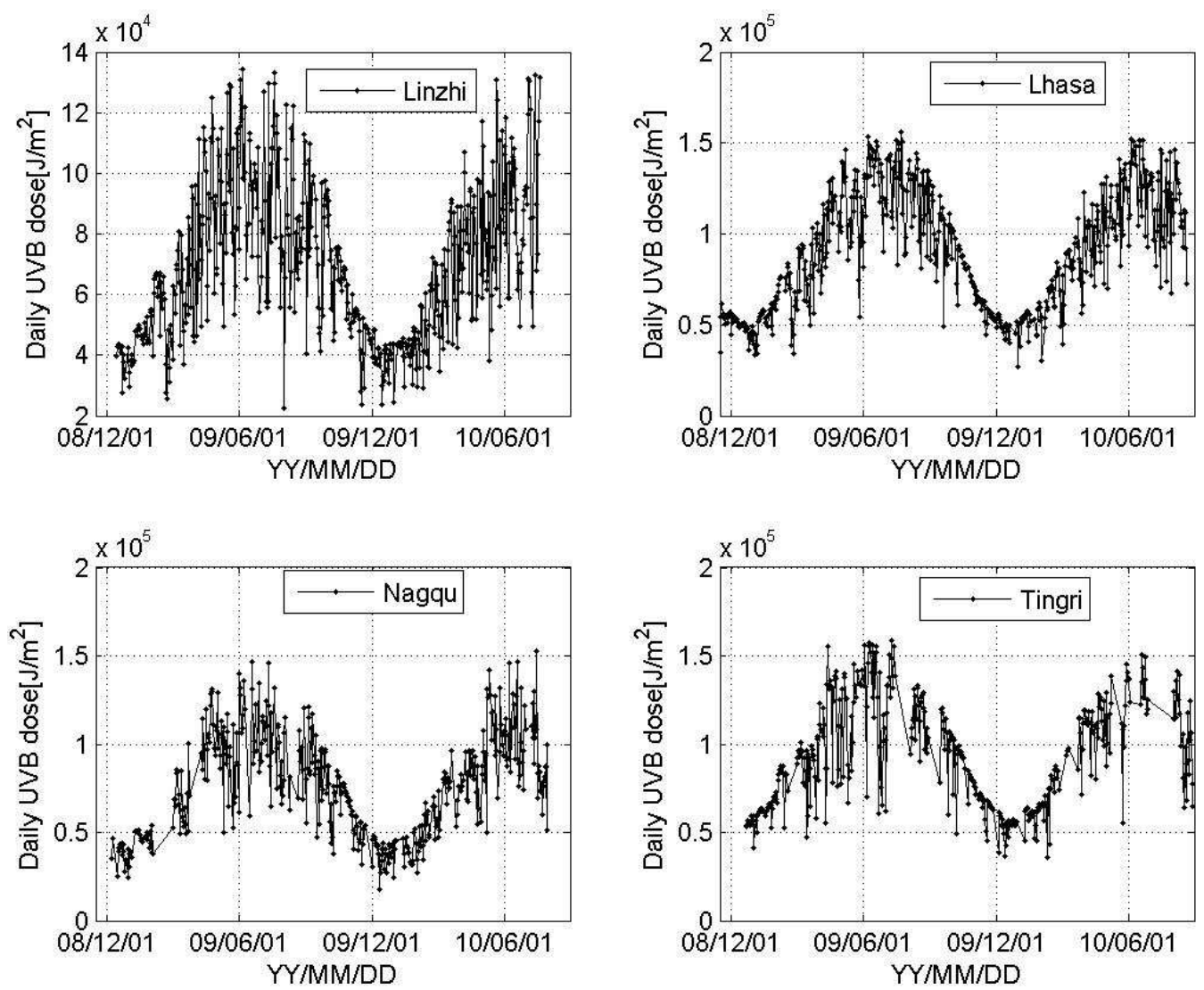

Figure 6: Measured daily UVB doses of the four sites in Tibet for the time period of Nov. 15, 2008 - Aug. 31, 2010.

Solar UVA radiation has special influence on erythemal irradiances inside homes, offices, cars, sunrooms and greenhouses since window glass, glass in sunrooms and greenhouses, vehicle glass and some brands of sunscreens act as a barrier to the shorter UVB wavelengths while transmitting some of the longer UVA wavelengths. Figure 7 shows that the UVA radiation level in Tibet is much larger than the UVB radiation level. It shows the measured solar UVA and UVB dose rates for a day in midsummer of 2009 in Tingri near Mt. Everest. The specific day was mainly clear-sky, not so much influenced by clouds. Figure 7 shows that on this specific day clouds at times reduced the UVA radiation level significantly. However, Figure 8 shows that the ratio of the UVB radiation to the UVA radiation increased, implying that clouds do not reduce UVB radiation as much as it reduces UVA radiation. The measurements show that the maximum 
value of the UVA irradiance for the specific day was $86.66 \mathrm{~W} / \mathrm{m}^{2}$ at 05:51GMT, while the maximum value of UVB irradiance for the day was only $6.97 \mathrm{~W} / \mathrm{m}^{2}$ at the same time, which is only $8.04 \%$ of the UVA irradiance. However, the percentage UVB/UVA ratio frequently exceeds this value due to clouds, as seen in Figure 8 where the maximum percentage reached $10.15 \%$. Figure 8 also shows that the percentage UVB/UVA ratio increases as the sun rises, and decreases as it sets. The percentage varied from $1.39 \%$ to $10.15 \%$ for that specific day in Tingri.

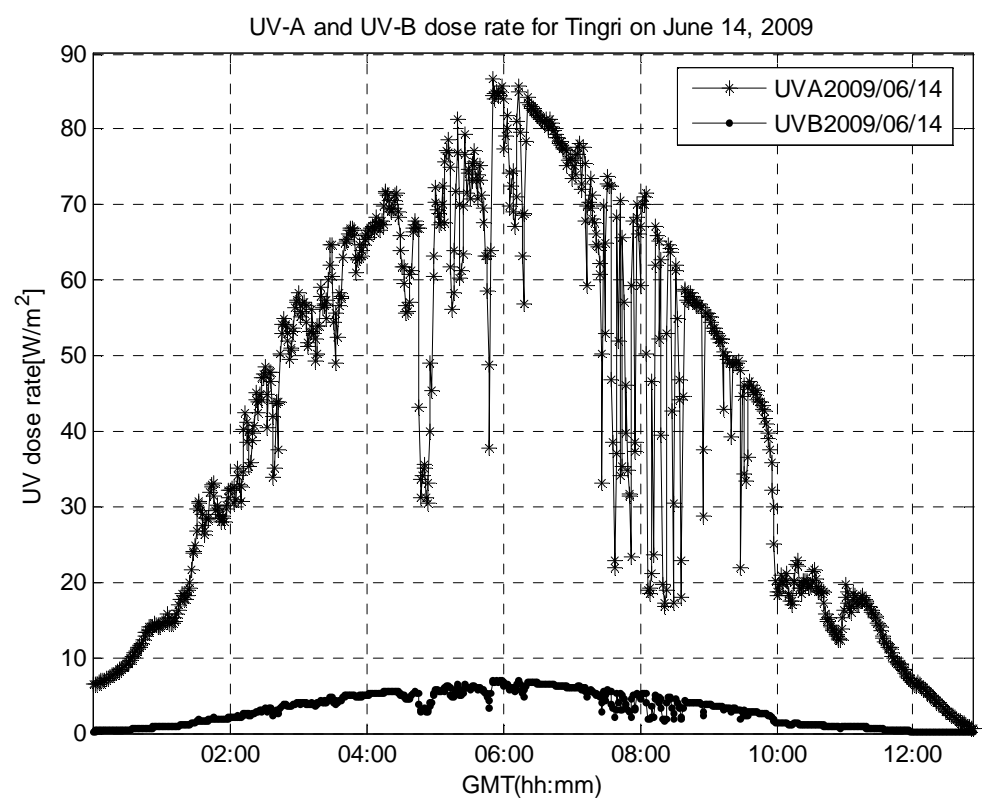

Figure 7: Measured UVA and UVB radiation levels in Tingri on June 14, 2009

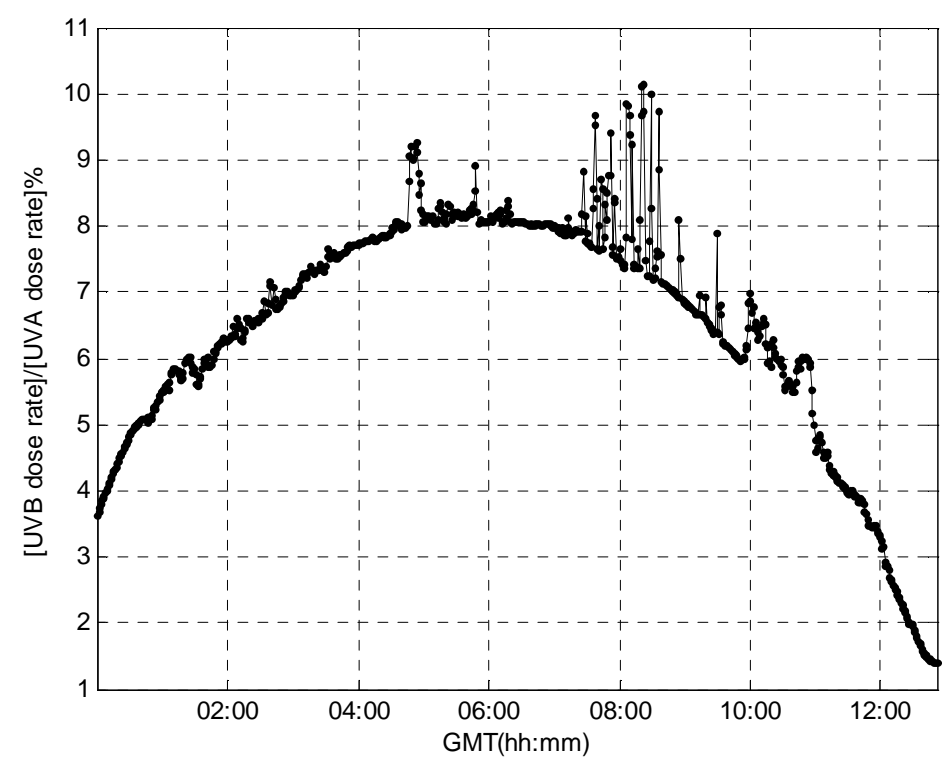

Figure 8: Diurnal variation of the ratio between UVA and UVB radiation levels at Tingri 


\section{Conclusions}

Solar UV radiation data measured at four sites in Tibet have been analyzed for the time period November, 2008 - August, 2010. For the first time results of ground-based measurements of solar UV irradiance in a large-scale region on the Tibetan plateau are analyzed and reported. We used a new version of NILU-UV irradiance meters, which received absolute calibration in Norway before taking measurement in Tibet, and which were subjected to frequent relative calibration at each site. Therefore, the presented measured results are accurate.

The derived results include CIE weighted erythemal solar UV irradiance at the four sites of Lhasa, Linzhi, Nagqu, and Tingri in Tibet, where the erythemal UV dose rates were found to vary between $0.99 \mathrm{~kJ} / \mathrm{m}^{2}$ and $9.1 \mathrm{~kJ} / \mathrm{m}^{2}$ during the measurement period. Comparison of erythemal UV irradiances between the four sites showed that Tingri had the highest value around the year among the four sites in Tibet.

A longer-term (2004 to 2010) UV measurement results for Lhasa was also presented, showing the UV irradiance level in Lhasa for the period from 2004 to 2010 to be relatively stable.

Measured results for the solar UVA and UVB radiation in Tibet were also presented, and quantitative values of the daily-integrated UVB dose for each station were reported. Comparison of UVA and UVB irradiances was made by selecting a specific day in Tingri. The results showed that the maximum UVA irradiance for the day was $86.66 \mathrm{~W} / \mathrm{m}^{2}$, while the maximum UVB irradiance was only $6.97 \mathrm{~W} / \mathrm{m}^{2}$. The percentage UVB/UVA ratio varied from $1.39 \%$ to $10.15 \%$ during that specific day in Tingri.

\section{Acknowledgements}

We thank the Norwegian Cooperation Programme for Development, Research and Higher Education (NUFU) for funding the project (PRO2007/10193N) 'Spatial and Seasonal Variation in Solar Radiation and Aerosol Concentrations and Compositions in Urban and Rural Sites in Himalayan Region', and the Network for University Co-operation Tibet-Norway for funding the project 'Environmental Physics Research in Tibet'. Also, we thank the National Natural Science Foundation of China for funding the project 'Ground-based measurements of Solar UV Radiation in Tibet' (project code: 41065009).

\section{REFERENCES}

[1] Zhou X. and Luo C., Ozone valley over the Tibetan Plateau, Acta Meteorological Sinica, 8, 505-506, 1994.

[2] Liu Y., Li W., Zhou X. and He J., Mechanism of Formation of the Ozone Valley over the Tibetan Plateau in Summer Transport and Chemical Process of Ozone, Adv. Atmos.

Sci., 20, 103-109, 2003. 
[3] Hester R. E. and Harrison R. M., Causes and Environmental Implications of Increased UV-B Radiation, Issues in Environmental Science and Technology, 14, Royal Society of Chemistry, Cambridge, UK, 2000.

[4] Urbach F., The Biologic Effects of Ultraviolet Radiation, with Emphasis on the Skin, Geographic Pathology of Skin Cancer, F. Urbach, Ed. (Oxford: Pergamon Press), pp. 635-650, 1969.

[5] Norsang G., LiWei Ma, Dahlback A., Zhuoma C., Tsoja W., Porojnicu A., Lagunova Z. and Moan J., The Vitamin D Status Among Tibetans, Photochem. Photobiol., 85, 10281031. DOI: 10.1111/J.1751-1097.2009.00552.x., 2009.

[6] Norsang G., Kocbach L., Tsoja W., Stamnes J. J., Dahlback A., and Nema P., Ground-based measurements and modeling of solar UV-B radiation in Lhasa, Tibet. Atmos. Environm., 43, 1048-1502, 2009.

[7] Dahlback A., Norsang G., Stamnes J. J. and Gjessing Y., UV measurements in the 3000$5000 \mathrm{~m}$ altitude region in Tibet, J. Geophys. Res., 112, D09308, doi:10.1029/2006JD007700, 2007.

[8] Ci Ren P. B., Sigernes F., and Gjessing Y., Ground-based measurements of solar UVradiation in Tibet: preliminary results, Geophys. Res. Lett., 24, 1359-1362, 1997.

[9] www.nilu.no/products, as of 10 April 2011.

[10] McKinlay A. and Diffey B., A reference action spectrum for ultraviolet induced erythema in human skin, Commission International de l'Eclarirage (CIE) - Journal, 6 , $17-22,1987$.

[11] Dahlback A., Measurements of biologically effective UV doses, total ozone abundances, and cloud effects with multichannel, moderate bandwidth filter instruments, Appl. Opt., 35, 6514-6521, 1996.

[12] NILU PRODUCTS AS, www.nilu.no/products, The NILU-UV Irradiance Meter User's Manual, Version 2.1, 2008.

[13] Tevini M., (ed.), UVB Radiation and Ozone Depletion: Effects on Humans, Animal, Plants, Microorganism, and Materials, Lewis Publishers, Boca Raton, 1993. 